\title{
Effect of the leukotriene receptor antagonist MK-0679 on baseline pulmonary function in aspirin sensitive asthmatic subjects
}

\author{
Barbro Dahlén, Dorothy J Margolskee, Olle Zetterström, Sven-Erik Dahlén
}

\begin{abstract}
Background-The cysteinyl leukotrienes $\left(\mathrm{LTC}_{4}, \mathrm{LTD}_{4}\right.$, and $\mathrm{LTE}_{4}$ ) have been shown to mediate airway obstruction evoked by several factors which trigger asthmatic reactions-for example, allergen and exercise. Accordingly, drugs which block the action or formation of these leukotrienes are being evaluated as a new treatment of asthma. Elevated production of leukotrienes has been reported in asthmatic subjects who are intolerant to aspirin and related nonsteroidal anti-inflammatory drugs. In this study the influence of the specific leukotriene receptor antagonist MK-0679 was tested on basal airway function in asthmatic patients with documented aspirin intolerance.
\end{abstract}

Methods-The eight subjects in the study had a mean baseline $\mathrm{FEV}_{1}$ of $78 \%$ predicted (range 58-99\%) and six required treatment with inhaled glucocorticosteroids (400-1200 $\mu \mathrm{g}$ budesonidel beclomethasone daily). On two separate days the subjects received either $825 \mathrm{mg}$ MK-0679 or placebo, orally in a double blind, randomised, crossover design.

Results-The leukotriene antagonist MK-0679 caused bronchodilation which lasted for at least nine hours. The average peak improvement in $\mathrm{FEV}_{1}$ was $18 \%$ above the predrug baseline, but the bronchodilator response varied between $34 \%$ and $5 \%$ and was found to correlate strongly with the severity of asthma and aspirin sensitivity.

Conclusions-The findings indicate that ongoing leukotriene production may be one cause of persistent airway obstruction in aspirin sensitive asthmatic subjects and that they may benefit from treatment with a leukotriene receptor antagonist.

(Thorax 1993;48:1205-1210)

Aspirin sensitive asthma is a distinct disease entity which afflicts between $5 \%$ and $20 \%$ of adult asthmatic subjects and involves serious intolerance to aspirin as well as other nonsteroidal anti-inflammatory drugs. ${ }^{1}$ Often these asthmatic patients suffer from nasal symptoms (polyposis, loss of smell) and display a severe type of non-allergic asthma which runs a chronic course despite avoidance of non-steroidal anti-inflammatory drugs. ${ }^{2}$ The patients are frequently dependent on relatively high doses of inhaled steroids and sometimes continuous treatment with oral steroids is required to control their asthma. New therapeutic strategies in these patients are therefore needed and one possibility is anti-leukotriene drugs.

The leukotrienes are a group of arachidonic acid products which were discovered in 1979. ${ }^{34}$ The three closely related cysteinylcontaining leukotrienes, $\mathrm{LTC}_{4}, \mathrm{LTD}_{4}$, and $\mathrm{LTE}_{4}$, constitute the proposed mediator of asthma and inflammation, slow reacting substance of anaphylaxis (SRS-A). Thus, $\mathrm{LTC}_{4}$, $\mathrm{LTD}_{4}$ and $\mathrm{LTE}_{4}$ are potent constrictors of human airways, ${ }^{56}$ and mediators of allergen induced bronchial contractions in vitro. ${ }^{7}$ Furthermore, challenge studies in asthmatic subjects have shown that specific antileukotriene drugs attenuate airway obstruction induced by several triggers of asthma, including allergen, ${ }^{8-11}$ exercise, ${ }^{12}{ }^{13}$ and cold, dry air. ${ }^{14}$ Recently MK-0679, a specific leukotriene receptor antagonist, ${ }^{15}$ was found to block aspirin induced airway obstruction in aspirin sensitive asthmatics. ${ }^{16}$ It has also been convincingly shown that these patients release leukotrienes when provoked by acetylsalicylic acid. ${ }^{17-19}$ Of special interest are the findings that aspirin sensitive asthmatics have a higher basal production of leukotrienes than other asthmatics, ${ }^{17} 18$ and that they are hyperresponsive to inhalation of $\mathrm{LTE}_{4}{ }^{20}$ together providing additional indications that leukotrienes may be important mediators in this type of asthma.

The effect of the potent and specific leukotriene antagonist, MK-0679, on basal pulmonary function was therefore assessed in a group of well characterised aspirin sensitive asthmatic subjects. Recent observations in aspirin tolerant asthmatic patients ${ }^{21} 22$ indicate that leukotriene antagonists may cause acute bronchodilation. Since aspirin sensitive
7 April 1993 Revised version received

9 July 1993

Accepted 11 August 1993 
Table 1 Characteristics of subjects in study

\begin{tabular}{|c|c|c|c|c|c|c|c|}
\hline \multirow[b]{2}{*}{$\begin{array}{l}\text { Subject } \\
\text { no. }\end{array}$} & \multirow[b]{2}{*}{$\begin{array}{l}\text { Sex, age } \\
\text { (years) }\end{array}$} & \multicolumn{3}{|c|}{ History (in years) } & \multirow[b]{2}{*}{$\begin{array}{l}F E V_{1} \\
\text { (\% predicted) }\end{array}$} & \multirow{2}{*}{$\begin{array}{l}P D_{20} \\
\text { aspirin } \\
(\mu m o l)\end{array}$} & \multirow[b]{2}{*}{ Daily medication } \\
\hline & & $\begin{array}{l}\text { Aspirin } \\
\text { intolerance }\end{array}$ & Asthma & $\begin{array}{l}\text { Nasal } \\
\text { symptoms }\end{array}$ & & & \\
\hline 1 & M, 29 & 4 & 4 & 5 & 63 & 3 & IB(T:2.0 mg), OT(600 mg), IS(Bud:1200 $\mu \mathrm{g})$ \\
\hline 2 & $M, 60$ & 14 & 16 & 12 & 64 & 50 & IB(T:0.5 mg prn), OT(400 mg), IS(Bud: $800 \mu \mathrm{g})$ \\
\hline 3 & $F, 43$ & 9 & 9 & 20 & 95 & 126 & IB (T: $<0.5 \mathrm{mg})$ \\
\hline 4 & M, 53 & 9 & 9 & 9 & 99 & 92 & IB(S:0.6 mg), IS(Bec:400 $\mu \mathrm{g})$ \\
\hline 5 & $F, 35$ & 26 & 26 & 11 & 70 & 70 & IB(T:1.0 mg), IS(Bud:800 $\mu \mathrm{g})$ \\
\hline 6 & M, 24 & 4 & 8 & 8 & 79 & 3 & IB(S:4.0 mg), OT(900 mg), IS(Bud:1200 $\mu \mathrm{g}$ ) \\
\hline 7 & $\mathrm{M}, 47$ & 9 & 9 & 10 & 58 & 82 & IB $(T: 1.5 \mathrm{mg})$ \\
\hline 8 & $\mathrm{~F}, 31$ & 4 & 4 & 5 & 99 & 307 & IB(T:0.5 mg prn), IS(Bud:800 $\mu \mathrm{g})$ \\
\hline Mean & 40 & 10 & 11 & 10 & 78 & $42^{\star}$ & IB: $\mathrm{n}=2$ \\
\hline Range & $24-60$ & 4-26 & $4-26$ & $5-20$ & $58-99$ & 3-307 & $\begin{array}{l}\mathrm{IB}+\mathrm{IS}: \mathrm{n}=3 ; \\
\mathrm{IB}+\mathrm{IS}+\mathrm{OT}: \mathrm{n}=3\end{array}$ \\
\hline
\end{tabular}

${ }^{\star}$ Geometric mean. IB-inhaled $\beta$ stimulant (T-terbutaline, S-salbutamol); IS—inhaled steroid (Bud-budesonide, Bec-beclomethasone); OT-oral theophylline.

asthmatics are intolerant to many anti-inflammatory drugs, another study objective was to test the acute safety and tolerability of a leukotriene antagonist such as MK-0679 in this group of patients before initiating longer clinical trials.

\section{Methods}

PATIENTS

Eight non-smoking asthmatics (table 1) were selected for the study on the basis of aspirin intolerance documented by previous oral or bronchial challenge, or an unequivocal history. The study was approved by the local ethics committee and the patients gave informed consent. For inclusion in the study, treatment with systemic corticosteroids, inhaled cromolyn, oral bronchodilators or long acting antihistamines was not allowed; use of inhaled bronchodilators, oral theophylline or inhaled corticosteroids (daily dose of budesonide $\leqslant 1200 \mu \mathrm{g}$ ) was acceptable. Reversibility of airway obstruction was required as shown by an increase of at least $15 \%$ in forced expiratory volume in one second $\left(\mathrm{FEV}_{1}\right)$ after inhalation of nebulised salbutamol $1 \mathrm{ml}$ of a $2.5 \mathrm{mg} / \mathrm{ml}$ solution through a Spira Electro II dosimeter ${ }^{16}$ (Respiratory Care Center, Finland and Aspira Medical, Sweden). In order to establish current aspirin sensitivity all patients underwent a prestudy challenge involving inhalation of rising doses of lysine aspirin to determine the $\mathrm{PD}_{20} \mathrm{FEV}_{1}$ - that is, the provocative dose of acetylsalicylic acid $(\mu \mathrm{mol})$ producing a $20 \%$ fall in $\mathrm{FEV}_{1}{ }^{16}$

\section{STUDY DESIGN}

The study was carried out in a double blind, placebo controlled two period crossover design. The subjects entered the clinic at around $7.30 \mathrm{am}$. Doses of 75,250 and 500 $\mathrm{mg}$ (cumulative dose $825 \mathrm{mg}$ ) MK-0679 or placebo tablets were given at 30 minute intervals. The tablets were taken on an empty stomach and blood samples for MK-0679 assay were drawn before dosing and $60 \mathrm{~min}$ utes after the last tablet. Pulmonary function was followed as $\mathrm{FEV}_{1}$ on a spirometer (Vitalograph MDI Compact) using the best of three efforts at each time point. Baseline (predrug) $\mathrm{FEV}_{1}$ was defined as the mean of two recordings 15 minutes apart. Further recordings were obtained every 10 minutes during the period of tablet intake and thereafter at one, two, three, four, six, eight and 12 hours after treatment. Throughout the study patients were allowed to continue their regular asthma therapy except for withholding oral theophylline for 24 hours, inhaled steroids for 12 hours, and inhaled $\beta$ agonists for eight hours before a visit to the clinic. However, subject no 6 was permitted to use $\beta$ agonist in the mornings because of severe asthma; the dose $(0.8 \mathrm{mg}$ salbutamol) and the timing (three hours before MK-0679 or placebo) of the inhaled $\beta$ agonist was identical on the separate treatment days. Asthma treatment was withheld during the test day, but the protocol allowed for rescue treatment if considered necessary on clinical grounds.

After the 12 hour pulmonary function measurement, patients went home for the night but returned to the clinic the nex morning for general follow up including physical examination, spirometry measure ments, and blood sampling for routine haematology and blood chemistry. The placebo and active drug treatment days followed an identical protocol, but were at leas three days apart.

\section{ASSAYS}

The plasma concentration of MK-0679 was measured by high performance liquid chromatography as previously described. ${ }^{23}$

\section{STATISTICS}

The analysis of variance model of Grizzle was used to compare means between treatment groups. The ANOVA model contained terms for sequence, patient within sequence, period, and treatment. The normality assumption of the ANOVA was tested and verified with the Shapiro-Wilk statistic. Hartley's maximum $F$ test on the variance of the residuals was used to verify the homogeneity of variance assumption. Spearman's rank order test was used to correlate drug responses with subject characteristics. Results are generally reported as means (SD) and considered to be 
Figure 1 Basal pulmonary function $(F E V)$ followed in eight aspirin sensitive asthmatic patients for 12 hours after ingestion of placebo or MK-0679. Data are expressed as mean (SD) \% change of baseline FEV, (mean of first two recordings upon arrival at clinic) during each study day. The difference between placebo and $M K$ 0679 is significant ( $p$ $\leqslant 0.05)$ at all time points except when indicated (NS-non-significant, $p>$ $0.05)$.

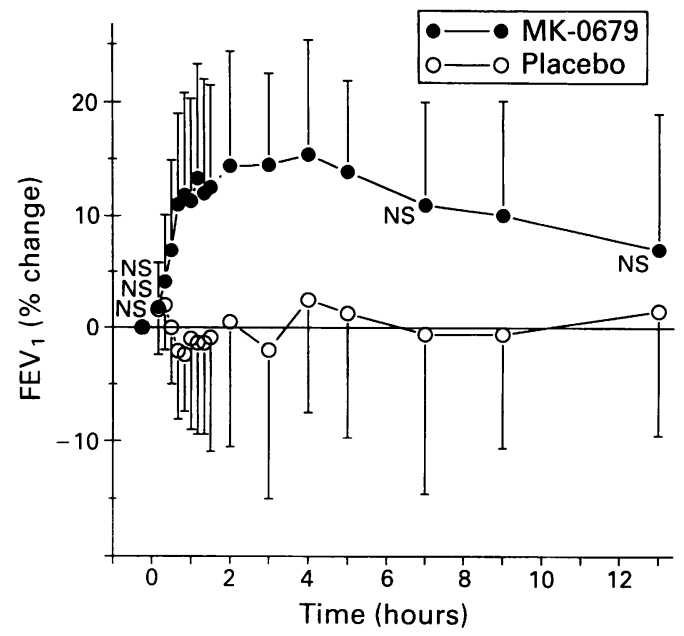

significantly different if two tailed tests give $\mathrm{p} \leqslant 0.05$. A digitising table and an IBM personal computer were used to measure areas under the curve (AUC) of $\mathrm{FEV}_{1} v$ time, employing as software SigmaScan (Jandel Scientific, Sausalito, California, USA) for planimetry and Basic Balance (Elsevier, Amsterdam, The Netherlands) for statistics.

\section{Results}

All patients completed the study without subjective or objective signs of drug related side effects. There were no differences in mean baseline $\mathrm{FEV}_{1}$ values between the two study days $(3 \cdot 0(0 \cdot 3) 1[82.8(15) \%$ predicted] and $2 \cdot 8(0.3) 1[78.4$ (17)\% predicted] for the placebo and MK-0679 treated days, respectively). Placebo or drug were given as three doses 30 minutes apart, reaching a total cumulative dose of $825 \mathrm{mg}$ for MK-0679. The mean plasma level of MK-0679 at one hour after dosing was $55(13) \mu \mathrm{g} / \mathrm{ml}$, which is more than ten times higher than the concentration documented to cause a 25 -fold displacement of the dose-response relation for inhaled $\mathrm{LTD}_{4}$ in asthmatic patients. ${ }^{24}$

After MK-0679 administration there was an improvement in $\mathrm{FEV}_{1}$ (fig 1). The effect occurred by 30 minutes after intake of active drug and was significantly different from placebo at all time points thereafter up to five hours after drug administration. The maximum response occurred between one and five hours after the drug and the mean increase above the morning pretreatment values varied between $11 \%$ and $15 \%$ at all time points (fig 1).

The mean maximal improvement in FEV was $18(9 \cdot 8) \%$ calculated from the peak effect in each individual. For comparison, inhalation of a nebulised solution of salbutamol $(2500 \mu \mathrm{g})$ produced a $22 \cdot 8(12 \cdot 2) \%$ improvement of $F E V_{1}$ in this group of subjects.

The maximal improvement in $\mathrm{FEV}_{1}$ after MK-0679, however, varied between $5 \%$ and $34 \%$. The extent of each subject's response to MK-0679 was therefore compared with three variables $\left(\mathrm{FEV}_{1} \%\right.$ predicted, medications required for control of asthma, and aspirin sensitivity) related to the clinical status (table 1). For each variable the rank order between the subjects was also determined (table 2). The area between the curve for $\%$ change in $\mathrm{FEV}_{1} v$ time and the zero reference line (AUC) was calculated for each treatment day (with decreases from the zero line expressed as negative areas, fig 1), and this overall measure of the response was used to analyse relations between subject characteristics and drug response. Firstly, for the group as a whole there was a significant improvement in mean AUC after MK-0679 compared with placebo $(18 \cdot 2(6)$ units and $-0.49(7)$ units, $p \leqslant 0.05)$. The change in AUC after drug (AUC $_{M K-0679}$ $-\mathrm{AUC}_{\text {placebo }}$ ) showed a weak tendency to correlate inversely with baseline $\mathrm{FEV}_{1} \%$ predicted (fig 2A). There was a good correlation between the bronchodilator response to the drug and the individual's sensitivity to aspirin, expressed as prestudy $\mathrm{PD}_{20}$ for aspirin (fig 2B). Moreover, when the response to MK-0679 was related to the sum of each subject's rank order score for $\mathrm{FEV}_{1} \%$ predicted and asthma medication there was an excellent correlation with the improvement in airway function produced by MK-0679 (table 2 and fig 2C).

A similar strong correlation $(r=0 \cdot 84$,

Table 2 Relations between subject characteristics and drug response. The subjects are grouped in rank order of severity (1-8; 1 = worst) for the variables below and, by additions, a rank order score for asthma severity and total disease severity is obtained

\begin{tabular}{|c|c|c|c|c|c|c|c|c|}
\hline \multirow[b]{2}{*}{$\begin{array}{l}\text { Subject } \\
\text { no. }\end{array}$} & \multicolumn{3}{|l|}{ Variables } & \multicolumn{3}{|c|}{ Sum of rank orders } & \multicolumn{2}{|c|}{ Drug response } \\
\hline & $\begin{array}{l}I^{\star} \\
F E V_{1} \\
\text { (\% } \\
\text { predicted) }\end{array}$ & $\begin{array}{l}I I^{\star} \\
\text { Asthma } \\
\text { medication }\end{array}$ & $\begin{array}{l}I I I^{\star} \\
P D_{20} \\
\text { aspirin } \\
(\mu \mathrm{mol})\end{array}$ & $\begin{array}{l}I+I I \dagger \\
\text { Asthma } \\
\text { severity } \\
\text { score }\end{array}$ & $\begin{array}{l}I+I I+I I I \\
\text { Total } \\
\text { rank order } \\
\text { score }\end{array}$ & $\begin{array}{l}\text { Overall } \\
\text { rank order } \\
\text { according } \\
\text { to } I+I I+I I I\end{array}$ & $\begin{array}{l}\text { Rank } \\
\text { order of } \\
\text { response }\end{array}$ & $\begin{array}{l}A U C \ddagger \\
M K-0679 \\
\text { - placebo }\end{array}$ \\
\hline 1 & 2 & 2 & 1 & 4 & 5 & 1 & 1 & $48 \cdot 3$ \\
\hline 2 & 3 & 3 & 3 & 6 & 9 & 3 & 2 & $39 \cdot 3$ \\
\hline 3 & 6 & 8 & 7 & 14 & 21 & 8 & 7 & $-2 \cdot 8$ \\
\hline 4 & 7 & 6 & 6 & 13 & 19 & 6 & 5 & $12 \cdot 5$ \\
\hline 5 & 4 & 4 & 4 & 8 & 12 & 4 & 8 & $-4 \cdot 8$ \\
\hline 6 & 5 & 1 & 1 & 6 & 7 & 2 & 3 & $37 \cdot 8$ \\
\hline 7 & 1 & 7 & 5 & 8 & 13 & 5 & 4 & $18 \cdot 6$ \\
\hline 8 & 7 & 5 & 8 & 12 & 20 & 7 & 6 & 0.2 \\
\hline$r^{5}$ & 0.57 & $0 \cdot 71$ & 0.81 & 0.81 & 0.84 & & & \\
\hline $\mathbf{p}$ & $0 \cdot 15$ & 0.04 & 0.01 & 0.02 & 0.01 & & & \\
\hline
\end{tabular}

${ }^{\star}$ Raw data in table 1 ; fused as abscissa in fig $2 \mathrm{C}$; fused as ordinate in figs $2 \mathrm{~A}-\mathrm{C}$; (Spearman's correlation coefficient $v$ drug response (AUC-increase, rightmost column), two-tailed significance of correlation indicated by $p$ value. 

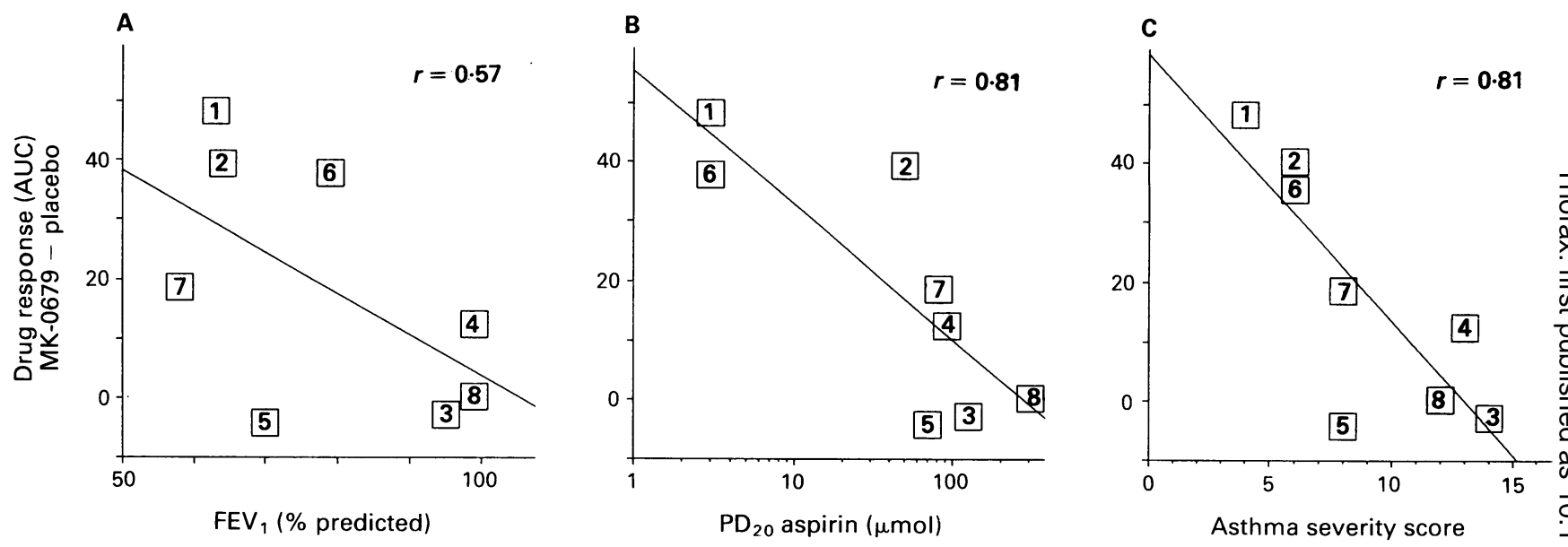

Figure 2 Relation between drug effect on airway function (expressed as difference in AUC, MK-0679 minus placebo) and subject characteristics with respect to different variables. (A) Baseline FEV, \% predicted (table 1). (B) Sensitivity to aspirin expressed as log transformed prestudy PD 20 for aspirin (table 1). (C) An arbitrary index of asthma severity (the sum of the rank order of baseline FEV, \% predicted and asthma medication for each subject, see table 2). Numbers within squares identify the subject behind each data point (see tables 1 and 2). Spearman's correlation coefficient indicated in figure, levels of significance shown in table 2.

$\mathrm{p}<0.01$ ) was found between the sum of the rank order score for all three variables and the drug response (table 2).

Only two subjects required rescue treatment during the study days. Subject no. 1 (tables 1 and 2) was given an inhalation of $0.5 \mathrm{mg}$ terbutaline at 10 hours during the drug treatment day. Subject no. 6 (tables 1 and 2) was given three inhalations of terbutaline, oral theophylline $600 \mathrm{mg}$, and inhaled budesonide $1200 \mu \mathrm{g}$ during the placebo day but needed no rescue after MK-0679.

\section{Discussion}

Oral administration of cumulative doses of the specific leukotriene receptor antagonist, MK-0679, caused significant improvement in basal lung function in this group of aspirin sensitive asthmatic subjects. The group mean maximal improvement was $18 \%$, which suggests that about $80 \%$ of the reserve for dilation was reached, as estimated by the bronchodilation achieved by inhalation of nebulised salbutamol. The bronchodilation persisted for at least nine hours after completion of dosing and the drug was well tolerated by the participants.

Concerning the mechanism behind the bronchodilation produced by MK-0679, it is well documented that this drug, as well as other members of the present generation of leukotriene antagonists, is a very specific receptor antagonist without smooth muscle relaxant properties. ${ }^{1525}$ Initial studies with leukotriene antagonists in healthy human volunteers failed to show evidence of bronchodilation. ${ }^{26} 27$ Likewise, in allergen provocation tests of mildly atopic asthmatic subjects the prechallenge baseline pulmonary function was unaffected by leukotriene antagonist administration. ${ }^{9}$ In vitro the baseline tension of isolated bronchi from non-asthmatics is not reduced in response to these drugs. ${ }^{28}$ In contrast, Hui and Barnes ${ }^{21}$ observed that the leukotriene antagonist ICI-

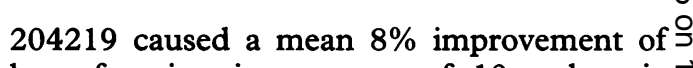
lung function in a group of 10 asthmatic $\vec{\nabla}$ patients with a mean $\mathrm{FEV}_{1}$ of $69 \%$ predicted. Gaddy et al $^{22}$ reported a $22 \%$ improvement in baseline $\mathrm{FEV}_{1}$ with the leukotriene antagonist $\overline{0}$ MK-571 in a group of 12 asthmatic patients with a mean $\mathrm{FEV}_{1}$ of $63 \%$ predicted. $\overrightarrow{0}$ Furthermore, the inhibitor of leukotriene biosynthesis, Zileuton, has also been found to induce significant bronchodilation in asthmatic subjects with reduced pulmonary function. ${ }^{29}$

Taken together, the available data indicate $\stackrel{\odot}{\varnothing}$ that anti-leukotriene drugs cause broncho- $\overrightarrow{\vec{F}}$ dilation in asthmatic subjects. It follows that $\stackrel{\circ}{3}$ ongoing leukotriene production in the airways may be a prerequisite for a bronchodilator response to these drugs. It is possible that the production of leukotrienes is proportional to the degree of airway inflammation ${ }^{19} 3031$ which $\stackrel{0}{x}$ generates the hypothesis that the broncho- $\frac{0}{3}$ dilator response would be related to variables linked to asthma severity. Gaddy et al ${ }_{3}$ reported a correlation with baseline $\mathrm{FEV}_{1}{ }^{22}$ but by using $\mathrm{FEV}_{1} \%$ predicted as a single variable of lung function it was not possible $\frac{T}{0}$ to obtain evidence of a strong relation in this study (fig 2A). When the rank order score for $N$ $\mathrm{FEV}_{1} \%$ predicted and asthma drug require- N ment was added for each subject, however, N this arbitrary index of asthma disease severity 0 showed a strong correlation with the benefi- 0

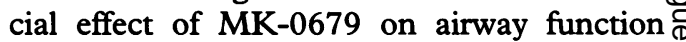
(fig 2C). Studies in larger groups of subjects $\stackrel{?}{+}$ are warranted to further examine which fac- $\underline{T}$ tors predict the proficiency of anti-leukotriene $\stackrel{\circ}{\circ}$ drugs as bronchodilators, but there seemed to be a striking association between the rank $\stackrel{\Phi}{\varrho}$ order of disease severity and the response to the leukotriene antagonist in this study.

It cannot be concluded from our observations whether the general severity of asthma or the degree of aspirin sensitivity was most important in determining the bronchodilator response to MK-0679. However, the data support the possibility that aspirin sensitive 
asthmatic patients benefit especially from anti-leukotriene drugs. Firstly, the bronchodilation response to MK-0679 correlated well with one index of aspirin sensitivity, the $\mathrm{PD}_{20}$ for acetysalicyclic acid in the group (fig 2B). Secondly, the magnitude of the improvement in $\mathrm{FEV}_{1}$ in this group of aspirin sensitive subjects was larger $(18 \% \quad v \quad 8 \%)$ than that reported by Hui and Barnes in a group of aspirin tolerant asthmatics with lower baseline pulmonary function (mean $\mathrm{FEV}_{1} 68 \%$ predicted compared with $78 \%$ in this study). In fact, it approached the degree of bronchodilation $(22 \%)$ produced by $\mathrm{MK}-571$ in the study of Gaddy et al where the asthmatic patients had significantly worse lung function (mean $\mathrm{FEV}_{1} 63 \%$ predicted) than in our study. ${ }^{22}$

The tested leukotriene antagonist was effective in subjects also treated with inhaled corticosteroids, which raises the possibility that leukotriene antagonists may provide added benefit when administered concomitantly with inhaled steroids to patients with aspirin sensitivity. This hypothesis deserves further study in aspirin sensitive and other steroid dependent asthmatics. In addition, the efficacy of the leukotriene antagonist in the steroid treated patients is of theoretical interest. It is commonly believed that corticosteroids abrogate formation of all arachidonic acid metabolites, the presumed mechanism being inhibition of the phospholipase step which is required for liberation of arachidonic acid from the cell membrane before its further cellular transformations. However, there is increasing evidence from in vitro studies - for example, of isolated human neutrophils-that corticosteroids generally do not inhibit leukotriene production. ${ }^{32}$ In support of this observation, systemic treatment with glucocorticoids failed to alter urinary excretion of $\mathrm{LTE}_{4}$ (considered to be a useful index of systemic production of cysteinyl leukotrienes) either at baseline $\mathrm{e}^{32} 33$ or after allergen inhalation challenge in asthmatic patients. ${ }^{34}$ It is possible, therefore, that leukotriene antagonists may add to the existing treatment strategies by blunting components of the airway inflammation that are unaffected by steroids.

There are indications that leukotrienes may also mediate obstruction of the upper airways. ${ }^{35}$ Since nasal symptoms including loss of smell are particularly prominent in the syndrome of "aspirin asthma" (the clinical triad of asthma, nasal polyposis and aspirin sensitivity $^{2}$ ), it may be more than anecdotal to mention that the most aspirin sensitive patient in this study spontaneously reported the return of his ability to smell (lost for many years) when treated with MK-0679. This observation has initiated ongoing studies to evaluate whether or not anti-leukotriene drugs will alleviate the nasal problems from which this group of patients suffer.

In conclusion, the findings support the theory that leukotriene antagonism may provide a new therapeutic alternative in aspirin sensitive asthmatic subjects who often suffer from a particularly severe variety of asthma. Recent observations suggest that anti-leukotriene drugs may block a final common path for many different factors which trigger asthmatic reactions-for example allergen, ${ }^{8-10}$ exercise, ${ }^{1213}$ dry cold air, ${ }^{14}$ inhalation of platelet activating factor ${ }^{36}$-as well as aspirin in aspirin sensitive asthmatics. ${ }^{16}$ While there are indications that leukotriene antagonism may also reduce bronchial hyperresponsiveness, 9 further studies must be carried out before it can be established that this class of drugs has anti-inflammatory properties. Nevertheless, it appears very likely that antileukotriene drugs will emerge as a rational new strategy for the treatment of asthma.

Supported by grants from the Swedish Medical Research Council (project 14X-9071), the Swedish Heart Lun Foundation, the Swedish Association Against Asthma and Allergy (RmA), the Institute of Environmental Medicine, the Swedish Environment Protection Board (31204), Karolinska Swedish Environment Protection Board (31204), Karolinska
Institute and an operating grant from Merck Research Institute and

Laboratories.

We thank Ms Christina Larsson and Ms Heléne Blomqvis for dedicated technical assistance, and Drs Reynold Specto and Anthony Ford-Hutchinson at Merck and Per Hedqvis and Bengt Samuelsson at Karolinska Institutet for support and encouragement.

1 Szczeklik A. Analgesics and Nonsteroidal anti-inflammatory drugs. In: deWeck AL, Bundgard H, eds. Allergic reactions to drugs. Handbook of experimental pharmacology. Vol 63. Berlin. Springer Verlag, 1983:277-98.

2 Samter M, Beers RF. Intolerance to aspirin. Clinical studies and consideration of its pathogenesis. Ann Intern Med 1968;68:975-83.

3 Samuelsson B, Dahlén S-E, Lindgren JÅ, Rouzer CA Serhan CN. Leukotrienes and lipoxins: structures, biosynthesis, and biological effects. Science 1987;237: 1171-6.

4 Lewis RA, Austen KF, Soberman RJ. Leukotrienes and other products of the 5-lipoxygenase pathway. Biochemistry and relation to pathobiology in human diseases. $N$ Engl f Med 1990;323:645-55.

5 Dahlén S-E, Hedqvist P, Hammarström S, Samuelsson B Leukotrienes are potent constrictors of human bronchi. Nature 1980;288:484-6.

6 Holroyde MC, Altounyan REC, Cole M, Dixon M Elliott EV. Bronchoconstriction produced in man by leukotrienes C and D. Lancet 1981;6:17-8.

7 Dahlén S-E, Hansson $G$, Hedqvist $P$, Björck $T$ Granström E, Dahlé B. Allergen challenge of lung tissue from asthmatics elicits bronchial contraction that correlates with the release of leukotrienes $\mathrm{C}_{4}, \mathrm{D}_{4}$, and $\mathrm{E}_{4}$. Proc Natl Acad Sci USA 1983;80:1712-6.

8 Dahlén S-E, Dahlén B, Eliasson E, Johansson H, Björck $\mathrm{T}$, Kumlin $\mathrm{M}$, et al. Inhibition of allergic bronchoconstriction in asthmatics by the leukotriene-antagonist ICI-204, 219. In: Samuelsson B, Ramwell PW, Paoletti R, Folco GC, Granström E, eds. Advances in prostaglandin, thromboxane and leukotriene research. Vol. 21. New York: Raven Press, 1990:461-4.

9 Taylor IK, O'Shaoughnessy KM, Fuller RW, Dollery CT. Effect of cysteinyl-leukotriene receptor antagonist ICI 204,219 on allergen-induced bronchoconstriction and airway hyperreactivity in atopic subjects. Lancet 1991;337:690-4.

10 Rasmussen JB, Eriksson L-O, Margolskee DJ, Tagari P Williams V, Andersson KE. Leukotriene $D_{4}$ recepto blockade inhibits the immediate and late bronchoconstrictor responses to inhaled antigen in patients with asthma. $f$ Allergy Clin Immunol 1992;90:193-201.

11 Friedman BS, Bel EH, Tanaka W, Han YHR, Spector R Sterk P. The effect of a leukotriene biosynthesis inhibitor (MK-886) on allergen-induced bronchoconstriction and leukotriene production in asthmatic subjects. Am Rev Respir Dis 1993;147:839-44.

12 Manning PJ, Watson RM, Margolskee DJ, Williams VC, Schwartz II, O'Byrne PM. Inhibition of exerciseinduced bronchoconstriction by MK-571: a potent induced bronchoconstriction by $\mathrm{MK}-571$ : a potent leukotriene $\mathrm{D}_{4}$,

13 Finnerty JP, Wood-Baker R, Thomson H, Holgate ST. Role of leukotrienes in exercise-induced asthma. Inhibitory effect of ICI 204,219, a potent leukotriene D receptor antagonist. Am Rev Respir Dis 1992;145:746-9.

14 Israel E, Dermarkarian $R$, Rosenberg $M$, Sperling $R$ Taylor G, Rubin P, et al. The effects of a 5-lipoxygenase inhibitor on asthma induced by cold, dry air. $N$ Engl $\mathcal{f}$ Med 1990;323:1740-4.

15 Jones TR, Zamboni R, Belley M, Champion E, Charette 
L, Ford-Hutchinson AW, et al. Pharmacology of L-660, 711 (MK-571): a novel potent and selective leukotriene $\mathrm{D}_{4}$ receptor antagonist. Can $\mathcal{F}$ Physiol Pharmacol 1989; 67:17-28.

16 Dahlén B, Kumlin M, Margolskee DJ, Larsson C, Blomqvist $\mathrm{H}$, Zetterström $\mathrm{O}$, et al. The leukotrienereceptor antagonist MK-0679 blocks airway obstruction induced by bronchial provocation with lysine-aspirin in induced by bronchial provocation with lysine-aspirin in 1018-26.

17 Christie PE, Tagari P, Ford-Hutchinson AW, Charlesson $\mathrm{S}$, Chee $\mathrm{P}, \mathrm{Arm} \mathrm{JP}$, et al. Urinary leukotriene $\mathrm{E}_{4}$ concentrations increase after aspirin challenge in aspirinsensitive asthmatic subjects. Am Rev Respir Dis 1991; 143:1025-9.

18 Kumlin $M$, Dahlén $B$, Björck $T$, Zetterström $O$, Granström E, Dahlén S-E. Urinary excretion of leukotriene $E_{4}$ and 11-dehydro-thromboxane $B_{2}$ in response to bronchial provocations with allergen, aspirin, leukotriene $\mathrm{D}_{4}$ and histamine in asthmatics. $\mathrm{Am}$ Rev Respir Dis 1992;146:96-103.

19 Knapp HR, Sladek K, Fitzgerald GA. Increased excretion of leukotriene $\mathrm{E}_{4}$ during aspirin-induced asthma. $f \mathrm{Lab}$ Clin Med 1992;119:48-51.

20 Arm JP, O'Hickey SP, Spur BW, Lee TH. Airway responsiveness to histamine and leukotriene $\mathrm{E}_{4}$ in subjects with ASA-induced asthma. Am Rev Respir Dis 1989;140: 148-53.

21 Hui KP, Barnes NC. Lung function improvement in asthma with a cysteinyl-leukotrine receptor antagonist. Lancet 1991;337:1062-3.

22 Gaddy IN, Margolskee DJ, Bush RK, Williams VC, Busse WW. Bronchodilation with a potent and selective leukotriene $\mathrm{D}_{4}\left(\mathrm{LTD}_{4}\right)$ receptor antagonist $(\mathrm{MK}-571)$ in asthma patients. Am Rev Respir Dis 1992;146:358-63.

23 Tocco DJ, DeLuna FA, Duncan EW, Hseih JH, Lin JH. Inter-species differences in stereoselective protein binding and clearance of MK-571. Drug Metab Dispos 1990;18:388-92.

24 Kips J, Margolskee D, DeLepeleire I, Joos G, Williams V, Buntix A, et al. MK-0679 is a potent and selective $\mathrm{LTD}_{4}$ antagonist in asthmatic men. Am Rev Respir Dis 1991;143:A599.

25 Synder DW, Giles RE, Keith RA, Yee YK, Krell RD. The in vitro pharmacology of ICI 198,615: a novel, potent and selective peptide leukotriene antagonist. $f$ Pharmacol Exp Ther 1987;243:548-6.

26 Smith LH, Geller S, Ebright L, Glass M, Thyrum PT. Inhibition of leukotriene $\mathrm{D}_{4}$-induced bronchoconstriction in normal subjects by the oral $\mathrm{LTD}_{4}$ receptor antagonist ICI 204,219. Am Rev Respir Dis 1990;141: 988-92.

27 Kips JC, Joos GF, DeLepeleire I, Margolskee DJ, Buntix A, Pauwels R, et al. MK-571: a potent antagonist of $\mathrm{LTD}_{4}$ induced bronchoconstriction in the human. $\mathrm{Am}$ Rev Respir Dis 1991;144:617-21.

28 Björck T, Dahlén S-E. Leukotrienes and histamine are the exclusive mediators of IgE-dependent contractions of $\omega$ human bronchi in vitro. Pulmonary Pharmacol 1993; 6:87-96.

29 Israel E, Rubin P, Pearlman H, Cohn J, Drazen J. 5lipoxygenase inhibition by Zileuton causes acute bronchodilation in asthma. Am Rev Respir Dis 1992;145:A16.

30 Taylor GW, Taylor I, Black P, Maltby NH, Turner N, Fuller RW, et al. Urinary leukotriene $\mathrm{E}_{4}$ after antigen challenge and in acute asthma and allergic rhinitis. challenge and in acute
Lancet 1989;i:584-8.

31 Drazen JM, O'Brien J, Sparrow D, Weiss ST, Martins $\mathrm{MA}$, Israel $\mathrm{E}$, et al. Recovery of leukotriene $\mathrm{E}_{4}$ from the urine of patients with airway obstruction. Am Rev Respir Dis 1992;146:104-8.

32 Sebaldt RJ, Sheller JR, Oates JA, Roberts LJ II, FitzGerald GA. Inhibition of eicosanoid synthesis by $\frac{\overrightarrow{ }}{\infty}$ glucocorticoids in humans. Proc Natl Acad Sci USA 1990;87:6974-8.

33 Manso G, Baker AJ, Taylor IK, Fuller RW. In vivo and in vitro effects of glucocorticosteroids on arachidonic acid metabolism and monocyte function in non asthmatic of humans. Eur Respir f 1992;5:712-6.

34 Taylor IK. Release of urinary leukotriene $E_{4}$ in asthmatic subjects: a review. In: Samuelson $B$, Dahlén SE, Fritsch $\mathrm{J}$, Hedqvist P, eds. Advances in prostaglandin, thromboxane and leukotriene research. Vol. 23 (in press).

35 Knapp HR. Reduced allergen-induced nasal congestion and leukotriene synthesis with an orally active 5-lipoxygenase inhibitor. N Engl f Med 1990;323:1745-8.

36 Kidney JC, Ridge SM, Chung KF, Barnes PJ. Inhibition of platelet-activating factor-induced bronchoconstriction by the leukotriene $\mathrm{D}_{4}$ receptor antagonist ICI 204,219. Am Rev Respir Dis 1993;147:215-7. 